Screening for emphysema via exhaled volatile organic compounds

This article has been downloaded from IOPscience. Please scroll down to see the full text article.

2011 J. Breath Res. 5046009

(http://iopscience.iop.org/1752-7163/5/4/046009)

View the table of contents for this issue, or go to the journal homepage for more

Download details:

IP Address: 131.174.33.226

The article was downloaded on 02/11/2012 at 14:05

Please note that terms and conditions apply. 


\title{
Screening for emphysema via exhaled volatile organic compounds
}

\author{
S M Cristescu ${ }^{1}$, H A Gietema ${ }^{2}$, L Blanchet ${ }^{3}$, C L J J Kruitwagen ${ }^{4}$, \\ P Munnik $^{5}$, R J van Klaveren ${ }^{6}$, J W J Lammers ${ }^{5}$, L Buydens ${ }^{3}$, \\ F J M Harren ${ }^{1}$ and P Zanen ${ }^{5}$
}

\author{
${ }^{1}$ Life Science Trace Gas Facility, Molecular and Laser Physics, Institute for Molecules and Materials, \\ Radboud University, Nijmegen, the Netherlands \\ ${ }^{2}$ Department of Radiology, University Medical Center, Utrecht, the Netherlands \\ ${ }^{3}$ Department of Analytical Chemistry/Chemometrics, Radboud University Nijmegen, Nijmegen, \\ the Netherlands \\ ${ }^{4}$ Julius Centre, University Medical Center, Utrecht, the Netherlands \\ ${ }^{5}$ Division of Heart and Lungs, University Medical Center, Utrecht, the Netherlands \\ ${ }^{6}$ Department of Pulmonology, Erasmus Medical Center, Rotterdam, the Netherlands \\ E-mail: simona@science.ru.nl,f.harren@science.ru.nl,h.gietema@umcutrecht.nl, \\ 1.blanchet@science.ru.nl, L.Buydens@science.ru.nl, C.L.J.J.Kruitwagen@umcutrecht.nl, \\ p.munnik@umcutrecht.nl, J.W.J.Lammers@umcutrecht.nl, p.zanen@umcutrecht.nl and \\ r.j.vanklaveren@erasmusmc.nl
}

Received 27 May 2011

Accepted for publication 3 October 2011

Published 10 November 2011

Online at stacks.iop.org/JBR/5/046009

\begin{abstract}
Chronic obstructive pulmonary disease (COPD)/emphysema risk groups are well defined and screening allows for early identification of disease. The capability of exhaled volatile organic compounds (VOCs) to detect emphysema, as found by computed tomography (CT) in current and former heavy smokers participating in a lung cancer screening trial, was investigated. CT scans, pulmonary function tests and breath sample collections were obtained from 204 subjects. Breath samples were analyzed with a proton-transfer reaction mass spectrometer (PTR-MS) to obtain VOC profiles listed as ions at various mass-to-charge ratios $(m / z)$. Using bootstrapped stepwise forward logistic regression, we identified specific breath profiles as a potential tool for the diagnosis of emphysema, of airflow limitation or gas-exchange impairment. A marker for emphysema was found at $m / z 87$ (tentatively attributed to 2 -methylbutanal). The area under the receiver operating characteristic curve (ROC) of this marker to diagnose emphysema was 0.588 (95\% CI 0.453-0.662). Mass-to-charge ratios $\mathrm{m} / \mathrm{z}$ 52 (most likely chloramine) and $m / z 135$ (alkyl benzene) were linked to obstructive disease and $m / z 122$ (most probably alkyl homologs) to an impaired diffusion capacity. ROC areas were 0.646 (95\% CI $0.562-0.730$ ) and 0.671 (95\% CI 0.524-0.710), respectively. In the screening setting, exhaled VOCs measured by PTR-MS constitute weak markers for emphysema, pulmonary obstruction and impaired diffusion capacity.
\end{abstract}

S. Online supplementary data available from stacks.iop.org/JBR/5/046009/mmedia

\section{Introduction}

For chronic obstructive pulmonary disease (COPD), the groups at risk are well defined and screening may allow identification of subjects in an early stage of the disease [1].
Emphysema, one of the components of COPD, is diagnosed via computed tomography (CT), by highlighting the areas with an abnormally low density [2]. Tissue density is expressed in Hounsfield units (HU) and the extent of emphysema is expressed as the percentage of the total lung volume below a 
density threshold [3]. The major drawbacks of CT scans are equipment immobility and radiation burden, although recent developments reduced the radiation dose significantly from 5 to 1 millisievert (mSv) [4]. Pulmonary function testing (PFT) is done easily and at lower costs, but the often used parameters from spirometry/flow-volume curves cannot detect emphysema when it is present without airflow limitation [5-7].

In the last decade, there has been an increased interest in exhaled breath analysis because the method is non-invasive, presents minimal risk to patients and allows large numbers of subjects to be investigated [8, 9]. The human breath contains volatile organic compounds (VOCs), which can serve as biomarkers. Proton-transfer reaction mass spectrometry (PTR-MS) is a promising tool for a rapid on-line determination of exhaled VOC profiles [10, 11].

The aim of the study presented in this paper was to explore breath analysis as a non-invasive method for the early detection of emphysema in heavy smokers at risk to develop COPD. The hypothesis is that emphysema is characterized by inflammation, which alters the composition of the exhaled air. The detection of airflow limitation or impaired gas-exchange was a secondary goal.

\section{Methods}

\subsection{Subjects}

The subjects included participated in the 'NELSONproject', a Dutch-Belgian multi-center lung cancer screening. Participants were current and former male smokers between 50 and 75 years old, who smoked $>15$ cigarettes per day during $>25$ years, or $>10$ cigarettes per day during $>30$ years and had $<10$ years of smoking cessation [12]. No prior diagnosis of either obstruction or emphysema was known. The trial was approved by the Dutch ministry of health (approval number 2000/04WBO). Subjects gave written informed consent. A waiver was received for the current analysis.

\subsection{CT Scanning and calculation of emphysema scores}

CT scanning was performed by a 16-detector-row scanner (Mx8000 IDT or Brilliance 16P, Philips Medical Systems, Cleveland, $\mathrm{OH})$ at $16 \times 0.75 \mathrm{~mm}$ collimation. Exposure settings were $30 \mathrm{mAs}$ at $120 \mathrm{kVp}$ for patients $\leqslant 80 \mathrm{~kg}$ and $30 \mathrm{mAs}$ at $140 \mathrm{kVp}$ for those $>80 \mathrm{~kg}$. Images were reconstructed at $1.0 \mathrm{~mm}$ slice thickness, at $0.7 \mathrm{~mm}$ increment, at $512 \times 512$ matrix and using a moderately soft filter (Philips 'B'). All CT scans were analyzed for the presence and extent of emphysema using in-house developed software, imageXplorer (iX), Image Sciences Institute, Utrecht, the Netherlands) [13-15].

Areas with an attenuation $<-950 \mathrm{HU}$ ( $=$ tissue density

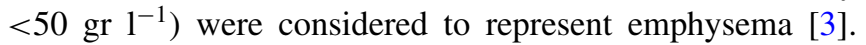
The emphysema score (ES) is the volume with attenuation below that threshold, expressed as percentage of the total lung volume. An ES $\geqslant 1 \%$ was considered as abnormal [16]. This threshold represents developing emphysema, as no emphysema should be present in healthy subjects.

\subsection{Pulmonary function tests}

Pulmonary function tests included the forced expiratory volume in $1 \mathrm{~s}\left(\mathrm{FEV}_{1}\right)$, forced vital capacity (FVC), the diffusing capacity for carbon monoxide (Dlco) and alveolar volume $\left(V_{\mathrm{A}}\right)$. Tests were conducted according to ERS guidelines, and abnormal pulmonary function values were defined as $\leqslant-1.64$ residual standard deviations below reference values [17].

On the day of the tests, participants refrained from smoking. They rested for 15 min upon arrival after which spirometry was performed, followed by flow-volume curves. The best of three attempts was selected for analysis. No reversibility testing was done. For descriptive purposes only, subjects were staged according to updated GOLD guidelines [18].

Diffusing capacity measurements were carried out after the spirometry and flow-volume curves. The inhalation mixture contained $0.3 \% \mathrm{CO}$ and $10 \%$ He with balance air. A breath-holding period of $10 \mathrm{~s}$ was used. Dlco was not corrected for haemoglobulin [19]. Dlco was corrected for $\mathrm{COHb}$ and divided by the alveolar volume $\left(\mathrm{Dlco} / V_{\mathrm{A}}\right)$.

\subsection{Exhaled breath sampling and measurement of VOCs}

Exhaled single breath samples were collected in Tedlar bags before PFT, using the method for the measurement of exhaled nitric oxide [20]. The sampling device is described in detail elsewhere [21]. In addition to each breath sample, the inhaled room air was also analyzed and if was found polluted, the corresponding breath sample was discarded.

The analysis of exhaled compounds was performed with a proton transfer reaction mass spectrometer (PTR-MS) [21-23]. Briefly, gases are ionized with $\mathrm{H}_{3} \mathrm{O}^{+}$ions, after which the product ions are mass analyzed and detected with a quadrupole mass spectrometer. VOCs are listed as ions at various mass-to-charge ratios $(\mathrm{m} / \mathrm{z})$.

The system was calibrated by mixing a variable flow of air free of hydrocarbons (by passing it through a catalyst at $350{ }^{\circ} \mathrm{C}$ ) with a fixed flow of $0.31 \mathrm{~h}^{-1}$ of a gas mixture of methanol, acetaldehyde, acetone, isoprene, benzene, toluene and xylene (molecular weights ranging from 32 to $106 \mathrm{amu}$ ) in concentrations of 1 ppmv $( \pm 5 \%)$ (Linde, Dieren, the Netherlands). In this way, calibration factors are obtained for these compounds converting ion intensity (in ncps, normalized counts per seconds) to gas mixing ratios (in ppbv, part per billion volume). From these conversion factors, the calibration factors (sensitivity) of other compounds at a specific $\mathrm{m} / \mathrm{z}$ ratio were calculated, taking into account the kinetic reaction constant $(k)$ for the proton-transfer reaction in the drift tube and transmission efficiency factors of the quadrupole mass spectrometer [11]. For several compounds the reaction constant is known; acetonitrile $(m / z 42)$ has $k=5.1 \times$ $10^{-9} \mathrm{~cm}^{3} \mathrm{~s}^{-1}$. Concentrations of the compounds which are not identified have been calculated based on a 'standard' reaction constant for protonation of $k=2.2 \times 10^{-9} \mathrm{~cm}^{3} \mathrm{~s}^{-1}$. This allows a first estimate of the respective concentration of an unknown compound (based on the measured count rate). 
Table 1. Demographic data (mean \pm SD) of subjects by GOLD stage.

\begin{tabular}{lllllll}
\hline Stage & Age $(\mathrm{yrs})$ & Pack years $^{\mathrm{a}}$ & $\mathrm{FEV}_{1}{ }^{\mathrm{b}}$ & $\mathrm{FEV}_{1} / \mathrm{FVC}(\%)$ & Dlco $^{\mathrm{b}}$ & Dlco $V_{\mathrm{A}}{ }^{\mathrm{b}}$ \\
\hline FEV $_{1} / \mathrm{FVC} \geqslant 0.70$ & $61.3 \pm 5.1$ & $38.0(29.7-46.2)$ & $100.8 \pm 14.2$ & $76.3 \pm 4.1$ & $95.6 \pm 13.1$ & $92.3 \pm 15.0$ \\
GOLD I & $62.7 \pm 5.2$ & $38.3(29.7-46.2)$ & $93.2 \pm 9.9$ & $64.6 \pm 4.3$ & $82.2 \pm 20.0$ & $72.9 \pm 16.9$ \\
GOLD II & $65.4 \pm 6.2$ & $46.2(38.7-49.7)$ & $70.3 \pm 7.4$ & $59.2 \pm 6.7$ & $78.7 \pm 19.5$ & $75.9 \pm 18.7$ \\
GOLD III & $61.8 \pm 6.4$ & $38.0(34.2-43.7)$ & $49.9 \pm 3.5$ & $44.0 \pm 7.6$ & $61.9 \pm 4.3$ & $59.9 \pm 3.1$ \\
\hline
\end{tabular}

${ }^{a}$ Median (25-75\%).

${ }^{\mathrm{b}}$ As percentage predicted.

The limit of detection (LOD) is considered from a signal-to-noise ratio $(\mathrm{S} / \mathrm{N})$ of 2 accordingly to $\mathrm{LOD}=2 \times$ $\mathrm{SD}_{\text {blank }} /$ sensitivity. The $\mathrm{SD}_{\text {blank }}$ represents the standard deviation of the background count rates determined by $\mathrm{SD}_{\text {blank }}=$ $\left(I_{\text {blank }} / \tau\right)^{1 / 2}$, where $I_{\text {blank }}$ is the intensity of the background signal (counts per second) and $\tau$ is the dwell time (1.5 s) [11]. The background signal was measured $2 \times 3$ cycles with the catalyst in the sampling line (clean air).

The Tedlar bags were tested earlier with respect to suitability for breath sampling and storage [24]. The collection method and the chemical analysis were validated for accuracy, precision, selectivity, limits of detection, sensitivity and reproducibility and last degradation of VOCs in the collection bag [24].

\subsection{Statistics}

We calculated means, standard deviations and $95 \%$ confidence intervals (CI) for normal distributed parameters and medians with the interquartile range for non-normal distributed ones.

Suitable markers from the spectrum were selected using stepwise forward logistic regression [25]. However, the $\sim 150$ mass numbers measured deliver an unfavorable case/variable ratio and the outcome of the logistic regression can be unstable. We approached this problem via bootstrapping, which takes a sample with replacement from the database and the logistic regression is run on that sample [26]. The $p$-value for entry was set at 0.15 and for removal at 0.30 in this initial selection phase. The outcome is a set of mass numbers that discriminate between 'emphysema' and 'no emphysema', and this set is stored. This procedure was repeated 500 times, generating 500 sets of markers. Now, stable and suitable markers will appear often in these 500 sets (ideally 100\%): the occurrence of each mass number in the 500 sets was therefore calculated. The markers with $a \geqslant 50 \%$ occurrence were selected and subjected to a confirmatory logistic regression.

This confirmatory logistic regression estimated the probability of an individual to belong to the diseased group, and these probabilities were used to calculate the area under the receiver operating characteristic curve (ROC): that area
Table 2. Median (25-75\% range) emphysema scores broken down by GOLD stage. Emphysema scores are depicted as the percentage lung volume $<-950 \mathrm{HU}$.

\begin{tabular}{ll}
\hline & Emphysema score $(\%)$ \\
\hline FEV $_{1} /$ FVC $\geqslant 0.70$ & $0.18(0.06-0.38)$ \\
GOLD I & $0.51(0.21-1.15)$ \\
GOLD II & $1.27(0.49-2.23)$ \\
GOLD III & $3.98(3.61-6.25)$ \\
\hline
\end{tabular}

renders the probability to diagnose emphysema or lowered $\mathrm{FEV}_{1} / \mathrm{FVC}$ and Dlco/ $V_{\mathrm{A}}$ values correctly.

Next to the above, a number of other statistical methods are available [27-29], and in the supplementary data (available at stacks.iop.org/JBR/5/046009/mmedia), we present the outcome of such methods. The advantage of this approach is that results obtained here are validated via alternative methods.

\section{Results}

A cohort of 204 subjects was recruited for this study; the characteristics are shown in table 1. Fifty-three subjects were classified as GOLD I, 25 as GOLD II and five subjects as GOLD III. No GOLD IV subjects were found. The median ES according to the GOLD stage are given in table 2. Of all subjects, $54.4 \%$ (95\% CI 47.4-61.3\%) still smoked; the smoking/non-smoking ratio in the groups with a lowered/normal $\mathrm{FEV}_{1} / \mathrm{FVC}$ was not different $(p=$ $0.766)$, nor was it in the group with/without emphysema $(p=0.199)$.

Acetonitrile, measured with PTR-MS at $m / z$ 42, is a known indicator for smoking, and it indeed discriminated well between ex- and current smokers $(p<0.001)$ (see table 3 ) [30]. The ROC area was 0.831 (95\% CI 0.770-0.891).

Emphysema was diagnosed in 43 subjects $(21.1 \%, 95 \%$ CI 16.0-27.2\%). The bootstrapping approach delivered $\mathrm{m} / \mathrm{z}$ 87 as a marker (table 4). The median levels for $m / z \quad 87$ in emphysema subjects are higher, but the overlap in values is considerable. The ROC area to detect emphysema was 0.558 (95\% CI 0.453-0.662).

Table 3. Median (25-75\% range) of $m / z 42$ (acetonitrile) levels broken down by smoking status.

\begin{tabular}{|c|c|c|c|c|}
\hline \multicolumn{3}{|c|}{ LOD (ppbv) } & \multicolumn{2}{|c|}{ Median levels (25-75\% range) } \\
\hline$m / z$ & & $p$-value ${ }^{\mathrm{a}}$ & Current smoker (ppbv) & Ex-smoker (ppbv) \\
\hline 42 & 0.31 & $<0.001$ & $726(358.3-1078)$ & $116(74.6-188.3)$ \\
\hline
\end{tabular}


Table 4. Suitable $m / z$ to detect emphysema (levels in normalized counts $/ \mathrm{sec}$ ).

\begin{tabular}{|c|c|c|c|c|}
\hline \multicolumn{3}{|c|}{ LOD (ppbv) } & \multicolumn{2}{|c|}{ Median levels (25-75\% range) } \\
\hline$m / z$ & & $p$-value ${ }^{\mathrm{a}}$ & No emphysema (ppbv) & Emphysema (ppbv) \\
\hline 87 & 1.31 & 0.06 & $16.8(6.2-34.3)$ & $26.9(6.1-44.2)$ \\
\hline
\end{tabular}

${ }^{a} p$-values from the confirmatory logistic regression.

Table 5. Suitable $m / z$ to detect an abnormal FEV1/FVC.

\begin{tabular}{lllll}
\hline & LOD (ppbv) & & \multicolumn{2}{c}{ Median levels (25-75\% range) } \\
\cline { 4 - 5 }$m / z$ & & $p$-value $^{\mathrm{a}}$ & Normal FEV $_{1} / \mathrm{FVC}(\mathrm{ppbv})$ & Abnormal FEV $_{1} / \mathrm{FVC}(\mathrm{ppbv})$ \\
\hline 52 & 0.47 & 0.007 & $2.6(1.3-3.2)$ & $2.1(1.3-3.1)$ \\
135 & 0.82 & 0.002 & $1.8(1.2-2.6)$ & $2.2(1.4-3.1)$ \\
\hline
\end{tabular}

${ }^{a} p$-values from the confirmatory logistic regression.

Table 6. Suitable $m / z$ to detect an abnormal Dlco $/ V_{\mathrm{A}}$

\begin{tabular}{lllll}
\hline & LOD (ppbv) & & \multicolumn{2}{c}{ Median levels (25-75\% range) } \\
\cline { 3 - 5 }$m / z$ & & $p$-value $^{\mathrm{a}}$ & Normal $D_{\text {lco }} / V_{\mathrm{A}}(\mathrm{ppbv})$ & Abnormal $D_{\text {lco }} / V_{\mathrm{A}}(\mathrm{ppbv})$ \\
\hline 122 & 0.82 & 0.046 & $2(1.3-2.5)$ & $1.6(1-2.2)$ \\
\hline
\end{tabular}

${ }^{a} p$-values from the confirmatory logistic regression.

Eighty-three subjects $(40.7 \%$, 95\% CI $34.2-47.5 \%)$ showed a $\mathrm{FEV}_{1} / \mathrm{FVC}$ value below the lower limit of normal. The bootstrapping approach delivered $\mathrm{m} / \mathrm{z} 52$ and $\mathrm{m} / \mathrm{z} 135$ (table 5). The levels of $m / z 52$ are reduced in obstruction, but $m / z 135$ is not. The ROC area to detect an abnormal $\mathrm{FEV}_{1} / \mathrm{FVC}$ of this combination of markers was $0.646(95 \%$ CI 0.562-0.730).

Seventy-one $(34.8 \%, 95 \%$ CI 28.6-41.6\%) showed a $\mathrm{Dlco} / V_{\mathrm{A}}$ value below the lower limit of normal. The bootstrapping approach delivered $m / z \quad 122$ as a marker (table 6), which was reduced in diseased subjects. The ROC area to detect an abnormal Dlco $/ V_{\mathrm{A}}$ was 0.671 (95\% CI 0.524$0.710)$.

It is known that identification of compounds is notoriously difficult with PTR-MS, as one mass-to-charge ratio may be associated with a parent molecule, fragment of the parent molecules and/or clusters between water and small molecules with strong permanent dipole moments. A list with possible candidates for the four mass-to-charge ratios of interest for this study is given in table 7 . When known, the fragmentation ions are also specified.

A possible compound for $m / z 52$ is chloramine $\left(\mathrm{H}_{2} \mathrm{NCl}\right)$. For subjects with abnormal $\mathrm{FEV}_{1} / \mathrm{FVC}$, the identity of the ion at $m / z=52$ as chloramine is confirmed by the presence of the isotopic ion $m / z=54$ with an intensity of $6.5 \%$ which is close to the expected isotopic abundance of $7.2 \%$ (correlation coefficient of 0.8 ).

The ion $m / z$ 87, found as a marker for emphysema, is the parent ion of 2,3 butanedione (diacetyl), 2-or 3-pentanone, 2-or 3-methylbutanal (table 7). Apart from these, several other substances (not listed in the table) are suggested to be present in exhaled breath. In our instrument as well as in other reported studies [31, 32], the main contributions to these compounds are attributed to $m / z 87$ and 69 . For the emphysema subjects, the related percentage contributions for the ion traces at $\mathrm{m} / \mathrm{z}$
Table 7. List of possible compounds for the $m / z$ markers indicated in tables 4-6.

\begin{tabular}{|c|c|c|}
\hline Possible compounds & Related ions & References \\
\hline \multicolumn{3}{|l|}{$m / z 87$} \\
\hline Pentanal & 69, 87,41 & {$[45,32,33]$} \\
\hline 2,3-butanedione & $\mathbf{8 7}, 61,88,43$ & [46] \\
\hline 2-methyl-3-buten-2-ol (MBO) & $87, \mathbf{6 9}, 41$ & {$[31,32]$} \\
\hline 2-methylbutanal & 87,69 & [31] \\
\hline 2-pentanone & $\mathbf{8 7}, 45,88$ & [33], [32] \\
\hline 3-methyl-2-butanone & $\mathbf{8 7}, 88$ & [32] \\
\hline 3-methyl-2-buten-1-ol & $87, \mathbf{6 9}, 41$ & [31] \\
\hline 3-methyl-3-buten-1-ol & $87, \mathbf{6 9}, 41$ & [31] \\
\hline 3-methylbutanal & 87,69 & [31] \\
\hline 3-pentanone & 87,69 & {$[32]$} \\
\hline \multicolumn{3}{|l|}{$m / z 52$} \\
\hline Propiolonitrile & & [37] \\
\hline Chloramine & & [47] \\
\hline$m / z 122$ & & [37] \\
\hline \multicolumn{3}{|l|}{ Benzamide } \\
\hline \multicolumn{3}{|l|}{ 2,6-dimethyl-benzenamine } \\
\hline \multicolumn{3}{|l|}{ 4-aminobenzenecarbonal } \\
\hline \multicolumn{3}{|l|}{ 1-(4-pyridinyl)-ethanone } \\
\hline \multicolumn{3}{|l|}{ 1-(3-pyridinyl)-ethanone } \\
\hline \multicolumn{3}{|l|}{$n$-ethyl-benzenamine } \\
\hline \multicolumn{3}{|l|}{ Benzeneethanamine } \\
\hline \multicolumn{3}{|l|}{$N, N$-dimethyl-benzenamine } \\
\hline \multicolumn{3}{|l|}{ 2-propyl-pyridine } \\
\hline \multicolumn{3}{|l|}{ 2-(1-methylethyl)-pyridine } \\
\hline Other alkyl homologs & & [36] \\
\hline$m / z 135$ & & {$[32,37]$} \\
\hline \multicolumn{3}{|l|}{ sec-butylbenzene } \\
\hline \multicolumn{3}{|l|}{ 1,2,3-trimethylbenzene } \\
\hline 1,3,-diethylbenzene & $\mathbf{1 3 5}, 79$ & \\
\hline \multicolumn{3}{|l|}{ 1,4,-diethylbenzene } \\
\hline \multicolumn{3}{|l|}{ n-butylbenzene } \\
\hline \multicolumn{3}{|l|}{ 1,2,-diethylbenzene } \\
\hline 1,2,3,5-tetramethylbenzene & & [48] \\
\hline 1,2,4,5-tetramethylbenzene & & \\
\hline
\end{tabular}

In bold are the major fragments. 
87 and 69 are $80 \%$ and $20 \%$, respectively, and the linear correlation coefficient between the two ions of 0.8 . Hence, we indicate as the most probable candidate 2-methylbutanal and exclude several compounds with $m / z 69$ as the major fragment, such as pentanal, 2-or 3- methyl-2- or 3-buten-1 or 2-ol, etc.

For ketones such as 2,3 butanedione or 2-pentenone, hardly any fragmentation is reported so far. The protonated molecular ion is the most abundant mass, often followed by the isotopic ion [33]. In the emphysema patients, a weak correlation was found between $\mathrm{m} / 87$ and $\mathrm{m} / \mathrm{z} 88$ (linear correlation coefficient of 0.3 ). Moreover, the isotopic ion at $\mathrm{m} / \mathrm{z} 88$ is highly influenced by the presence of N,N-dimethylacetamide, a compound released by the Tedlar bags [24]. Based on these considerations, we cannot assess $\mathrm{m} / \mathrm{z} 87$ to any of the two ketones mentioned above.

Peroxyacetyl nitrate (PAN) was reported as a possible source of $m / z 122$ in selected ion flow tube mass spectrometry (SIFT-MS) [34] using $\mathrm{H}_{3} \mathrm{O}^{+}$as primary ions. However, in the PTR-MS $m / z 122$ undergoes subsequent reaction with water, and therefore, $m / z 77$ is used instead for PAN detection [35]. Possible compounds for $m / z 122$ are the alkyl homologs as found in breath analysis with PTR-MS [36, 37].

The ion $m / z 135$ is attributed to alkyl benzene compounds [32] (table 7).

\section{Discussion}

Markers in exhaled breath appear to be weakly related to emphysema and pulmonary function outcome in this screening setting. In other settings, more favorable characteristics and/or markers may be found [38].

The challenge in the field of exhaled VOCs is the selection of suitable markers from a wide range, which can be done based on an in-depth knowledge of the inflammatory processes and the VOCs generated. This requires prior definition of markers and often represents an educated guess (candidate marker approach). A scanning approach, like in genetic genome wide scans, can be more fruitful. One of the problems of this approach is that the outcome can be highly sample dependent, due to the unfavorable case/parameter ratio [39]. One way to deal with that problem is to chart the degree of sample dependence via bootstrapping. As said, bootstrapping draws many samples from a dataset and in some the effects of e.g. influencing data points will be present. In such samples, the outcome is vastly different, and therefore we selected markers with a high prevalence in the bootstrap samples. Bootstrapping is also known to lead to a better extrapolation of the results, as the sampling error is reduced. The fact that a well-known smoking marker $(\mathrm{m} / \mathrm{z}$ 42) discriminated ex- from current smokers is reassuring and validates both the measurement system and the statistical approach [30]. Still, it is possible that this technique is less well suited for the purpose, therefore we decided to use several other methods, described in the supplement; none of these alternatives lead to another conclusion (for details, see the supplementary data available at stacks.iop.org/JBR/5/046009/mmedia).

Confounders (e.g. recent smoking, food, etc) may bias the outcome. However, smokers and ex-smokers are randomized over the emphysema/non-emphysema and over obstructed/non-obstructed groups. The smoking status was obtained before CT-scanning and pulmonary function tests were carried out. Smoking bias is therefore improbable. Further proof of a lack of (recent) smoking bias is that the smoking indicator acetonitrile does not appear as a marker in any of our analysis [30]. Similar arguments can be used to exclude food or other effects. Diseases such as lung cancer or $\alpha_{1}$-antitrypsin deficiency are also randomized over the groups as their presence was unknown at the time of sampling or their effects are negligible as these diseases are seldom in the general population $(\sim 1 \%$ of all COPD cases are due to $\alpha_{1}$-antitrypsin deficiency). All materials in contact with the in-/exhaled air were inert/non-absorbable, and hence they can also not influence the outcome.

As we aimed to detect emphysema within (former) heavy smokers, we did not include healthy (non-smoking) controls. The contrast between the groups studied would increase, favoring marker detection, but at the same time outcome would be difficult to extrapolate to COPD screening in smokers. Furthermore, a possible bias due to differences is smoking habits would have been introduced.

Despite a lack of bias and the sensitive measurements, we must conclude that the one emphysema marker we report is not a strong one. The area under the ROC (AUC) of 0.558 does not constitute a suitable marker: a 0.7 value is often considered as a minimum. For obstruction and gas-exchange problems, the results were slightly better, but still these markers also did not reach the 0.7 threshold. Furthermore, $\mathrm{m} / \mathrm{z} 87$ which is most probably assessed to 2-methylbutanal is weakly correlated with $m / z 42(r=0.272)$, indicating that it is not related to smoking.

There can be several explanations for the low AUCs of the ROC. First of all, the emphysema severity in this nonhospital-based cohort was limited, since severe COPD was an exclusion criterion for participation. Emphysema is a slowdeveloping disease and the amount of inflammation causing it can be low grade, and so the probability of exhaling distinct fingerprints will be equally low. We could have included subjects with severe emphysema, but as these constitute more advanced disease, we consider that approach as less useful. Emphysema needs to be addressed in an early stage to be able to prevent further deterioration. A recent cross-sectional case-control study with e-Nose reported a good discrimination between asthma and COPD, but not between COPD and nonsmoking controls [40]. The COPD subjects in that study were characterized by severe obstruction (post-bronchodilator $\mathrm{FEV}_{1} 57 \%$ of predicted) and are much more diseased than the subjects included in this study. We therefore propose as an explanation that COPD/emphysema in heavy smokers do not generate sufficiently different exhaled VOC profiles to be used as markers.

The second explanation can be that we used an unbiased selection of heavy smokers. Other exhaled breath studies on e.g. lung cancer, which report suitable markers, often used a case-control design [41, 42]. In such a design, diseased subjects are contrasted to healthy subjects in equal numbers, mostly after matching. Such a design modifies the 
characteristics by increasing the prevalence of disease and hence the contrast: it will be easier to find markers in such a high-contrast study. In screening studies, the prevalence of the disease is much lower, and it becomes much more difficult to select a few subjects amongst many non-diseased subjects. The lower the prevalence of a disease, the stronger the marker for disease must be or the less the overlap in marker values between groups to be able to detect the diseased subjects.

The third possible explanation lies in the type of instrument used. PTR-MS is suitable for detecting only a small amount of masses with satisfactorily speed and low detection limit (mass range up to $160 \mathrm{amu}$ ). Compounds with higher molecular weight which could be potential candidates are thus not considered. The identification of compounds measured by PTR-MS is always tentative. Alternative solutions to overcome these limitations include the use of ion traps, coupling of PTR-MS with GC, the very recently developed time-of-flight mass spectrometry in combination with PTRMS and the analytical techniques such as GC-MS or SIFTMS [43, 44]. However, in this discovery phase, this is not a disadvantage [40].

To summarize, in COPD and/or emphysema screening studies, exhaled VOCs have not provided valuable diagnostic information so far.

\section{Acknowledgments}

This work was supported by EU-FP6-NEST-ADVENTURE program ('The Optical Nose' project FP6-002504-2). The authors would like to thank the two anonymous reviewers for their critical and constructive comments, especially related to compounds identification.

\section{References}

[1] Calverley P M A 2000 COPD—Early detection and intervention Chest 117 365s-71s

[2] Muller N L, Staples C A, Miller R R and Abboud R T 1988 Density Mask - an objective method to quantitate emphysema using computed-tomography Chest 94 782-7

[3] Martinez F J et al 2006 Predictors of mortality in patients with emphysema and severe airflow obstruction Am. J. Respir. Crit. Care Med. 173 1326-34

[4] Brenner D J 2004 Radiation risks potentially associated with low-dose CT screening of adult smokers for lung cancer Radiology 231 440-5

[5] Zielinski J and Bednarek M 2001 Early detection of COPD in a high-risk population using spirometric screening Chest $119731-6$

[6] Stratelis G, Jakobsson P, Molstad S and Zetterstrom O 2004 Early detection of COPD in primary care: screening by invitation of smokers aged 40 to 55 years Brit. J. Gen. Pract. 54 201-6

[7] Gelb A F et al 1996 Contribution of emphysema and small airways in COPD Chest 109 353-9

[8] Phillips M et al 2003 Detection of lung cancer with volatile markers in the breath Chest $1232115-23$

[9] Risby T H and Tittel F K 2010 Current status of midinfrared quantum and interband cascade lasers for clinical breath analysis Opt. Eng. 49111123

[10] Lindinger W, Hansel A and Jordan A 1998 Proton-transfer-reaction mass spectrometry (PTR-MS): on-line monitoring of volatile organic compounds at pptv levels Chem. Soc. Rev. 27 347-54

[11] de Gouw J et al 2003 Sensitivity and specificity of atmospheric trace gas detection by proton-transfer-reaction mass spectrometry Int. J. Mass Spectrom. 223 365-82

[12] van Iersel C A et al 2007 Risk-based selection from the general population in a screening trial: selection criteria, recruitment and power for the Dutch-Belgian randomised lung cancer multi-slice CT screening trial (NELSON) Int. J . Cancer 120 868-74

[13] Schilham A M R, van Ginneken B, Gietema H and Prokop M 2006 Local noise weighted filtering for emphysema scoring of low-dose CT images IEEE Trans. Med. Imaging 25 451-63

[14] Sluimer I, Schilham A, Prokop M and van Ginneken B 2006 Computer analysis of computed tomography scans of the lung: a survey IEEE Trans. Med. Imaging 25 385-405

[15] van Rikxoort E M, de Hoop B, van de Vorst S, Prokop M and van Ginneken B 2009 Automatic segmentation of pulmonary segments from volumetric chest CT scans IEEE Trans. Med. Imaging 28 621-30

[16] Lambrechts D et al 2010 The 15q24/25 susceptibility variant for lung cancer and chronic obstructive pulmonary disease is associated with emphysema Am. J. Respir. Crit. Care Med. 181 486-93

[17] Quanjer P H et al 1993 Lung-volumes and forced ventilatory flows-report working party standardization of lung-function tests European-community for steel and coal—official statement of the European Respiratory Society Eur. Respir. J. Suppl. 16 5-40

[18] http://www.goldcopd.org/

[19] Stam H, Hrachovina V, Stijnen T and Versprille A 1994 Diffusing-capacity dependent on lung-volume and age in normal subjects $J$. Appl. Physiol. 76 2356-63

[20] ATS/ERS 2005 ATS/ERS recommendations for standardized procedures for the online and offline measurement of exhaled lower respiratory nitric oxide and nasal nitric oxide, 2005 Am. J. Respir. Crit. Care Med. 171 912-30

[21] Steeghs M M, Cristescu S M, Munnik P, Zanen P and Harren F J 2007 An off-line breath sampling and analysis method suitable for large screening studies Physiol. Meas. 28 503-14

[22] Boamfa E I, Steeghs M M L, Cristescu S M and Harren F J M 2004 Trace gas detection from fermentation processes in apples; an intercomparison study between proton-transfer-reaction mass spectrometry and laser photoacoustics Int. J. Mass Spectrom. 239 193-201

[23] Steeghs M M L et al 2006 On-line monitoring of UV-induced lipid peroxidation products from human skin in vivo using proton-transfer reaction mass spectrometry Int. J. Mass Spectrom. 253 58-64

[24] Steeghs M M L, Cristescu S M and Harren F J M 2007 The suitability of Tedlar bags for breath sampling in medical diagnostic research Physiol. Meas. 28 73-84

[25] Hosmer D and Lemeshow S 2000 Applied Logistic Regression 2nd edn (New York: Wiley)

[26] Mooney C and Duval R 1993 Bootstrapping: a Nonparametric Approach to Statistical Inference (Newbury Park: Sage Publications)

[27] Postma G J, Krooshof P W T and Buydens L M C 2011 Opening the kernel of kernel partial least squares and support vector machines Anal. Chim. Acta 705 123-34

[28] Vandeginste B G M et al 1998 Handbook of Chemometrics and Qualimetrics vol 20B (Amsterdam: Elsevier) pp 349-81

[29] Norgaard L, Bro R, Westad F and Engelsen S B 2006 A modification of canonical variates analysis to handle highly collinear multivariate data J. Chemometr. 20 425-35

[30] Jordan A, Hansel A, Holzinger R and Lindinger W 1995 Acetonitrile and benzene in the breath of smokers and 
nonsmokers investigated by proton-transfer reaction mass-spectrometry (PTR-MS) Int. J. Mass Spectrom. Ion Process. 148 L1-L3

[31] Fall R, Karl T, Jordon A and Lindinger W 2001 Biogenic C5VOCs: release from leaves after freeze-thaw wounding and occurrence in air at a high mountain observatory Atmos. Environ. 35 3905-16

[32] Warneke C, De Gouw J A, Kuster W C, Goldan P D and Fall R 2003 Validation of atmospheric VOC measurements by proton-transfer-reaction mass spectrometry using a gas-chromatographic preseparation method Environ. Sci. Technol. 37 2494-501

[33] Buhr K, van Ruth S and Delahunty C 2002 Analysis of volatile flavour compounds by proton transfer reaction-mass spectrometry: fragmentation patterns and discrimination between isobaric and isomeric compounds Int. J. Mass Spectrom. 221 1-7

[34] Hastie D R et al 2010 Real-time measurement of peroxyacetyl nitrate using selected ion flow tube mass spectrometry Rapid Commun. Mass Spectrom. 24 343-8

[35] Hansel A and Wisthaler A 2000 A method for real-time detection of PAN, PPN and MPAN in ambient air Geophys. Res. Lett. 27 895-8

[36] Berchtold C, Meier L and Zenobi R 2011 Evaluation of extractive electrospray ionization and atmospheric pressure chemical ionization for the detection of narcotics in breath Int. J. Mass Spectrom. 299 145-50

[37] Kushch I et al 2008 Compounds enhanced in a mass spectrometric profile of smokers' exhaled breath versus non-smokers as determined in a pilot study using PTR-MS J. Breath Res. 2026002

[38] Kharitonov S A and Barnes P J 2006 Exhaled biomarkers Chest 130 1541-6
[39] Hersh C P et al 2005 Attempted replication of reported chronic obstructive pulmonary disease candidate gene associations Am. J. Respir. Cell Mol. Biol. 33 71-8

[40] Fens N et al 2009 Exhaled breath profiling enables discrimination of chronic obstructive pulmonary disease and asthma Am.J. Respir. Crit. Care Med. 180 1076-82

[41] Phillips M et al 1999 Volatile organic compounds in breath as markers of lung cancer: a cross-sectional study Lancet 353 1930-3

[42] Preti G, Labows J N, Kostelc J G, Aldinger S and Daniele R 1988 Analysis of lung air from patients with bronchogeniccarcinoma and controls using gas-chromatography massspectrometry J. Chromatogr.-Biomed. Appl. 432 1-11

[43] Phillips $\mathrm{M}$ et al 1999 Variation in volatile organic compounds in the breath of normal humans J. Chromatogr. B 729 75-88

[44] Smith D and Spanel P 2005 Selected ion flow tube mass spectrometry (SIFT-MS) for on-line trace gas analysis Mass Spectrom. Rev. 24 661-700

[45] Schwarz K, Filipiak W and Amann A 2009 Determining concentration patterns of volatile compounds in exhaled breath by PTR-MS J. Breath Res. 3027002

[46] Steeghs M et al 2004 Proton-transfer-reaction mass spectrometry as a new tool for real time analysis of root-secreted volatile organic compounds in arabidopsis Plant Physiol. 135 47-58

[47] Storer M K, Dummer J D, Cook J, McEwan M and Epton J M 2011 Increased concentrations of breath haloamines are not detectable in airways inflammation using SIFT-MS J. Breath Res. 5037105

[48] Jobson B T and McCoskey J K 2010 Sample drying to improve HCHO measurements by PTR-MS instruments: laboratory and field measurements Atmos. Chem. Phys. 10 1821-35 